\title{
Conceptual model of comprehensive research metrics for improved human health and environment*
}

\author{
Modelo conceitual de indicadores de desempenho abrangentes \\ para a melhoria da saúde humana e do meio ambiente
}

Jill Engel-Cox ${ }^{1}$

Bennett Van Houten ${ }^{2}$

Jerry Phelps ${ }^{2}$

Shyanika Rose 3
${ }^{*}$ This article was originally published by Environ H ealth Perspect 116:583592 (2008). doi:10.1289/ ehp.10925 available via http://dx.doi.org/ [Online 12 February 2008] and is part of the scientific collaboration between Cien Saude Colet and EH P. This work was conducted under contract H H SP23320045006XI, Task Order

HH SP233000015T, "Program

Assessments and

Evaluations for

NIEHS." Theauthors

declarethey haveno competing financial

interests.

${ }^{1}$ Battelle M emorial Institute. 2101 Wilson Blvd., Suite 800, Arlington, VA 22201 USA.

engelcoxj@battelle.org

${ }^{2}$ Division of Extramural

Research and Training,

National Institute of

Environmental $\mathrm{H}$ ealth

Sciences, National

Institutes of $\mathrm{H}$ ealth,

Department of $\mathrm{H}$ ealth and

H uman Services, Research

Triangle Park, North

Carolina, USA.

${ }^{3}$ Battelle M emorial

Institute, Durham, North

Carolina, USA.
Abstract Performancemeasurement predominantly consisted of near-term outputs measured through bibliometrics, but the recent focus is on accountability for investment based on long-term outcomes. Our objectiveis to build a logic model and associated metrics through which to measure the contribution of environmental health research programs to improvements in human health, the environment, and the economy. We developed a logic model that defines the components and linkages between extramural environmental health research grant programs and the outputs and outcomes related to health and social welfare, environmental quality and sustainability, economics, and quality of life, focusing on the environmental health research portfolio of the National Institute of Environmental H ealth Sciences (NIEHS) Division of Extramural Research and Training and delineates pathways for contributions by five types of institutional partners in the research process. Themodel isbeing applied to specific N IEHS research applications and the broader research community. We briefly discuss two examples and discuss the strengths and limits of outcome- based evaluation of research programs.

Key words Conceptual model development, Environmental health research, M etrics development, Performance measurement, Research impact evaluation
Resumo A avaliação de desempenho comprendia predominantemente resultados de curto prazo avaliados através de bibliometria, mas recentemente a ênfase voltou-se à prestação de contas dos investimentos com base em resultadosa longo prazo. N osso objetivo écriar um modelo lógico e métricas associadas através dos quais possamos avaliar a contribuição de programas de pesquisa em saúde ambiental para melhorar a saúdehumana, o meio ambienteea economia. Desenvol vemosum modelo lógico quede fineos componentes eel os entre os programasdepesquisa em saúde ambiental extramuros subsidiadose os resultados relacionados à saúde e ao bem-estar social, qualidade ambiental e sustentabilidade, economia e qualidade de vida, com ênfase no portfólio de pesquisa em saúdeambiental do N ational Institute of Environmental H ealth Sciences (NIEHS), divisão de pesquisa e treinamento extramuros, delineando caminhos para as contribuições de cinco tipos de parceiros institucionais no processo depesquisa. 0 modelo está sendo usado em aplicações específicas do NIEH S ena comunidade de pesquisa como um todo. Analisamos brevemente dois exemplos e os pontos fortes e limitações da avaliação baseada em resultados dos programas de pesquisa.

Palavras-chave Desenvolvimento de modelo conceitual, Pesquisa em saúde ambiental, Desenvolvimento demétrica, Avaliação de desempenho, Avaliação de impacto de pesquisa 
The mission of the $\mathrm{N}$ ational Institute of Environmental Health Sciences (NIEHS) is to reduce the burden of human illness and dysfunction from environmental causes. This mission is furthered partly through funding of extramural research in science that focuses on the cellular and molecular basis of environmentally induced disease. Other types of projects funded as part of the extramural research portfolio includeepidemiologic and community-based participatory research, as well as worker training and education. NIEHS is achieving its mission by focusing on diseases for which there is a strong indication of an environmental component, and for which thereis high or increasing prevalence in the U.S. population (e.g., asth$\mathrm{ma})$; by fostering integrated research teams testing complex hypotheses that address the interplay of environmental and other factors, such as genetics, sex or gender, age, and lifestyle; and by developing initiatives identifying the complex factors in the environment that can increase the risk of disease by supporting basic research that develops thescientific basis for health decisions, as well as applied research that fills gaps in understanding of environmental health risks ${ }^{1}$.

Given the complexity and diversity of research, program evaluation iscritical to understanding and documenting the effectiveness of funded research in illuminating the linkages between the environment and human health. M andates such as the Government Performance and Results Act of 1993 have required research agencies to look beyond measures of output (e.g., publications produced) toward metrics related to longterm outcomes on public health. Guidance from the U.S. Office of Management and Budget Program Assessment Rating Tool (PART) requires that outcomes of a program (managed by a single entity) belinked to a clear set of program and agency goals, yet be external to the research program ${ }^{2}$. When reviewing fundamental research programs using the PART guidance, managers of these programs face significant challenges in demonstrating a link be tween traditional research outputs and outcomes ${ }^{3}$. $H$ ealth and environmental research organizations such as NIEHS have been challenged to define and measure outcomes distant in time and space from environmental health research ${ }^{4}$. Outcome based measures of accountability for research grants are inherently difficult, becauseby definition in theFederal Grants and Cooperative Agreement Act of 1977, grants have indirect benefit to and little substantial involvement by federal agencies.

The objective of this study was to develop a conceptual framework to measure the impact of environmental health research programs on human health, the environment, and the economy, even when the impact may be indirect or diffuse.

\section{Approach}

Describing a research portfolio as comprehensive and multidisciplinary as that of NIEHS and measuring its effect on environmental health require a strategic approach that acknowledges all of the potential components of the research process and the application of that research to society in order to ultimately improve human health and quality of life. To design this approach, we developed a comprehensive logic model describing the agency's extramural research portfolio from grant award through ultimate outcomes. Logic models are graphic depictions of the relationship between a program's activities and its intended outcomes 5,6 and help to explain a program's "theory" or the underlying structure of how the program is intended to work? ${ }^{7}$. Besides being an evaluation tool, a logic model can also help program managers describe, and make explicit, how program "performance" is designed to achieve outcomes ${ }^{8}$. Research programs have extended traditional program logic to illustrate how research contributes to topics that inform federal decisions about protective health standards (e.g., N ational Research Council ${ }^{9}$. To broaden this conception and to incorporate requirements for outcome-based program evaluation, our logic model of a research program provides a visual and conceptual representation of what broad impacts the research program is likely to haveand how theimpacts are achieved. Thesimplest structure that defines the impact of research on society is a linear progression: inputs $\rightarrow$ research activities $\rightarrow$ outputs $\rightarrow$ outcomes $\rightarrow$ ultimate outcomes. We chose this format because much of the theoretical and methodological literature describing the research process either explicitly or implicitly provides information on the inputs, activities, outputs, or outcomes of research, as well as describing how these elements of the research process can be linked to one anoth$\mathrm{er}^{10}$. Even though the process may not be linear, our focus is on the influence of specific research program inputs on a range of outcomes and does not attempt to evaluate all the influences of a particular outcome. Definitions of the logic model components are presented below. Inputs are resources that feed into the research program from NIEHS, other federal agencies, research institutions, and community and business partners (e.g., funding, 
staff qualifications, technical assistance, grantees, organizational resources, community resources). Activities are actions that describe how the inputs are used to carry out the research program or project (e.g., grant awarding, exposure/risk assessments). Outputs are the direct products of the research activities, such as publications, presentations, and new funding applications, as well as patents and products.

Outcomes are benefits or changes resulting from the use of the research outputs. Outcomes are defined further as short term, intermediate, long term, and ultimate. Assigning time frames to the four levels of outcomes is difficult, because the length of time taken is highly variable depending on the individual outcome and the many factors that may affect it. Short- to long-term outcomes may include:

. Translation into or adoption of policy or administrativedecisions, clinical guidelines, improved allocation of resources, setting of health targets, development of criteria for evaluative and inspectivebodies, commercial development and availability of products, behavioral changeamong practitioners, and the use of commercial products ${ }^{11,12}$.

. New and improved products and processes; methods of organizing, managing, and evaluating products and environments; improved safety of products and work environments; and individual and sector productivity rates ${ }^{13}$

. The incidence, magnitude, and duration of social change ${ }^{13}$.

U Itimate outcomes of environmental health research may include:

. Health and social welfare gain and national economic benefit from commercial exploitation and a healthy workforce ${ }^{11,12}$

. Environmental quality and sustainability, improved health care and healthy longevity, and provision of basic needs to the population ${ }^{13}$

. International balance of trade (i.e., the relation of exports to imports of various countries), energy independence, gross national product, and quality of life ${ }^{14}$.

Two other components of the logic model as they related to the NIEH Sextramural research portfolio include contextual factors and reservoir of knowledge. Contextual factors could potentially affect the research environment through availability of resources or shifts in research or policy priorities that create constraints or opportunities for the research program. Examples include political or society interests, external triggers such as a disease outbreak, state of the economy, and other national and global socioeconomic influences.
Reservoir of knowledge represents the accumulation of understanding, knowledge, and pre vious research that may or may not be directly related to the NIEHS extramural research portfolio but contributes to the development of and, in turn, is contributed to as a result of the research activities described within the model. This "knowledge pool" is difficult to measure concretely, but encompasses both research and the interaction of individuals that "interact and produce innovation and discovery through unpredictable paths and at uneven intervals" 3 .

\section{Conceptual logic model \\ and submodels for research metrics}

The logic model delineates separate pathways acknowledging contributions by theinstitutions partnering in the research process: NIEHS, other government (federal, state, and local) agencies, grantee institutions, business and industry, and community partners. Each institutional pathway contains specific logic model elements related to inputs, activities, outputs, and outcomes. Underlying each element are specific metrics (see Table 1 for examples).

Distinctionsdrawn between theinstitutional pathways are artificial to some degree, and there is considerable crossover between submodels. Generally, however, each pathway illustrates the research process that would be carried out most directly by a given institutional partner that is being evaluated. This should not be taken to imply that we consider the pathway shown to be the most influential on a particular outcome. In thefollowing sections, wefurther describethefiveinstitutional pathways and their components. Relationships between theinstitutions are represented by the arrows connecting components in different institutional pathways. However, relative strength and importance of these relationships cannot be determined from this model.

\section{Government pathway:} NIEHS and other agencies

This pathway describes the inputs, activities, outputs, and outcomes directly associated with the grant programs of both NIEHS and other government agencies (Table 1). Although this is a combined discussion of the two pathways, examples provided relate primarily to NIEHS. 
Table 1. Example metrics for logic model components.

ID Pathway component Example metrics

NIEHS and other government pathway

A NIEHS grant programs

A 1 Grant awarding

A2 Program formulation

A Information transfer

A4 Agency-funded research result dissemination

A 5 Awareness of research

A6 Policy assessments

A 7 Monitoring and surveillance

A 8 Identification of scientific needs/new science

A 9 Laws, regulations, standards

A10 New grant programs

A11 Improved environment

A12 Reduced human exposure

Grantee institution pathway

B1 Use of grant funds

B2 Investigator career development

B3 Training and certifications

B4 Grant-funded knowledge/products

B5 Communities of science

B6 Replication and new research

B7 Guidelines/recommendations

B8 Accumulation of knowledge

B9 Clinical practice changes
Amount of funding by year, by type

Number of research grants awarded by year, by type

Amount of funding for new initiatives or programs, by year, by type

Number of staff or grantee testimonies and briefings to decision makers, by year

Number of press releases (research results, program announcements), by year, by type; number of conferences sponsored by agency, by year

Number of professional conferences, workshops, and research events attended by NIEHS staff

Number of policy documents issued that cite NIEH S-funded research, by year

Number of monitoring/surveillance measures instituted citing NIEHS-funded research, by year

Number of new research opportunities identified in NIEHS strategy and planning documents

Number of regulations/standards that cite NIEHS-funded research in support documents, by year

Number of new initiatives or programs, by year, by

type; amount of funding for new initiatives or programs, by year, by type

Ambient air pollutant concentrations, by year; toxic chemical contamination in indoor environments by location, by year Pollutant concentrations and measures of exposed populations

Amount of funding by year, by source; number of investigators/fellows trained under each grant, by year Number of grants awarded to investigators by year, by source Number and type of certifications provided by investigators by year, by funding source

Number of presentations at selected key conferences by year, by grant type and funding source; number of peer-reviewed publications by year, by grant type and funding source Number of NIEH S-funded grants involving interdisciplinary/ cross-collegiate principal investigators; number of

M emoranda of Understanding between grantee institutions Number of citations of previously published research funded by NIEHS, by year (multiple years); impact factor of each citation as measured by ISI

Number of clinical guidelines published that cite NIEHSfunded research, by year Number of citations in the literature of previously published research funded by NIEHS, by year Type of self-reported changes in clinical practice reported by health care providers, by year 
Table 1. continuation

ID Pathway component Example metrics

Business and industry pathway

C1 Product development and cooperative research

Amount of industry funding matching NIEHS grant funding, by year; amount of Cooperative Research and Development

Agreement (CRADA) funding by year, by type

C2 U se of NIEHS research

C3 Patents and new drug applications

Number of industry trade publications that reference NIEHS research

N umber of patents that cite NIEHS-funded research, by year; number of new drugs or products that cite NIEHSfunded research in the patent

C4 Commercial products and drugs

Amount (dollars) from sale of products that cite NIEHSfunded research in the patent or were developed under a NIEHS CRADA, by year

C5 Awareness of environmental health impacts and regulations

N umber and source of voluntary programs undertaken by companies that cite NIEH S-funded research as supporting evidence, by year

C6 Operations change to reduce hazards

C7 Reduced emissions

N umber of products or drugs withdrawn from the market, by year; number of businesses that change operations to eliminate hazardous materials, by year

Air pollutant emissions inventory, by year; releases of toxics to all media, by year

Community pathway

D 1 Research facilitation

D2 Education and training

D 3 Community outreach

D 4 Public awareness

D5 Knowledge/attitude change

D 6 Behavior change/advocacy

E Ultimate outcomes

N umber of research projects participated in or facilitated in a community, by year

N umber of persons who receive formal training in a community, by year

Number of outreach events in a community, by year, by type N umber of public awareness campaigns citing NIEHS-funded research, by year

Surveys of public's knowledge and attitude changes regarding key NIEHS issues, by year

Surveys of public's behavior change with regard to key NIEHS issues or topics, by year

Trends in health care use/costs associated with exposures to adverse EH agents, by year; disease specific mortality rate, by year

Inputs

Inputs include funding and resources for NIEHS grant programs and programs of other related agencies such as the U.S. Environmental Protection Agency (EPA), Occupational Safety and Health Administration (OSHA), Food and Drug Administration (FDA), other members of the National Institutes of $\mathrm{H}$ ealth, and the Centers for Disease Control and Prevention. It also includes state and local government agencies that work to improve the environment and human health in their jurisdictions. 
Outputs

Outputs related to theNIEHS and government pathway include summary reports providing a synthesis of scientific information, press releases announcing research results or program activities, and information provided to legislative bodies as policy background. Related outputs are community outreach events conducted by NIEHS and other agencies (shown in thecommunity pathway).

\section{Outcomes}

NIEHS and other government outcomes include those in the short, intermediate, and long term.

. Short term, NIEHS: monitoring and awareness of ongoing research. NIEHS staff maintain an awareness of ongoing environmental health research, whether NIEHS funded or not, to keep abreast of emerging science.

. Short term, government: policy assessments. Before the enactment of new laws and regulations, governmental agencies conduct reviews of research and review recommendations to determine the potential impact of an issue on the environment and human health.

. Short term, government: monitoring and surveillance systems. M onitoring and surveillance measures are put in place by federal, state, or local governments to measure levels of environmental exposures or human disease, sometimes partly in responseto reports based on environmental health research. These may be new systems or adaptations of existing systems to measure emerging health hazards.

. Intermediate, NIEHS: identification of scientific needs and new science. Through ongoing monitoring and awareness of environmental health research, NIEHS is able to identify the scientific needs surrounding topics and emerging issues as well as the need for innovative science within the agency's mission.

. Intermediate, government: laws. Environmental and health-related laws develop from an improved understanding of the relationship between the environment and human health based partly on policy assessments made by NIEHS and other agencies. $M$ ajor new legislation is relatively rare (compared with regulations) and develops from a combination of awareness of a problem and connection to a policy solution. NIEHS work would most likely contribute to the identification of human environmental health issues.

. Intermediate, government: regulations and standards. Regulatory agencies such as theEPA, FDA, and OSH A (as well as state and local regulatory agencies) promulgateand enforceenvironmental and health regulations and standards. Regulations and standards published in the Code of Federal Regulations are justified in publicly available staff reports, criteria documents, and technical support documents.

. Long term, NIEHS: new grant programs. Given identification of scientific need and new science, NIEHS formulates new initiatives and programs. This activity is similar to that cited under "Activities" and essentially begins the grant-making process anew, advancing scientific understanding by building on earlier research.

. Long term, government: improved environment. Changes in regulatory standards should improvethe natural and built environment. There aremany potential measures for intermediate outcomes, so for any particular NIEH S research area, specific physical environmental measures would be selected. In general, these would fall into three broad categories: ambient air pollutant concentrations, lake/river/ocean groundwater quality, and/ or land use and soil contamination.

. Long term, government: reduced human exposureto environmental hazards. Reduced human exposure represents decreases in communities' or citizens' exposure to environmental hazards that result from regulations and standards. M easures for reduced human exposurearedrawn from measures of improvements in the built and natural environments with addition of the number of individuals located within a specified location.

\section{Grantee institution pathway}

This pathway describes the inputs, activities, outputs, and outcomes associated with grantee institutions and the research conducted by those institutions.

\section{Inputs}

The inputs describe the staff, financial, and organizational resources of the grantee institution receiving $\mathrm{NIEHS}$ funding. The resources are available to the grantee investigators to support the institutions' research program.

\section{Activities}

These describe the use of the grant funds provided by NIEHS by the grantee institutions. The 
activities includespecific types of research projects that are funded through grants as well as the development of interventions, tools and methods, and other products. Types of activities include basic, epidemiologic, and clinical research; intervention research and development; technology transfer/innovation research; exposureassessments; and training. Related to the activities of universities and other research institutions are the research and development activities of business and industry (shown in thebusiness and industry pathway) and the summary dissemination of results by NIEHS (shown in the NIEHS pathway).

\section{Outputs}

The outputs are the direct products of the grantee institution's use of NIEHS grant funds. They include tangible products such as presentations, publications, curricula, intervention, and certifications. They also includeless tangible products such as knowledge gained from research, new tools and methodologies, and the career development of investigators such as new funding applications, promotions, and membership in committees or working groups that may result from affiliation with NIEH S-funded research. Related to the outputs associated with grantee institutions and investigators is the public awareness of research activities and research results that affect their health and communities (shown in the community pathway), as well as the awareness of NIEHS staff of ongoing research (shown in the NIEHS pathway).

\section{Outcomes}

Thegrantee outcomes in the model include the following:

. Short term: communities of science. Communities of science are created when investigators working in the same or related areas develop relationships and research networks that contribute to the advancement of knowledge.

. Short term: replication and new research. The use of research findings typically depends upon compilation of evidencefrom multiple research studies. These can include replication of an initial study and new research that extends earlier studies.

. Intermediate: clinical guidelines and recommendations. Health institutes and professional societies publish clinical guidelines and recommendations related to practice, treatments, and drug use. These are developed based on research and clinical trials that may be funded by NIEHS.
- Intermediate: accumulation of knowledge. Replication and related new research, along with information drawn from other sources, contribute to the accumulation of knowledge and understanding about environmental health. It is the weight of evidence that drives changes in behavior as well as changes in funding priorities.

. Longterm: clinical practicechanges. Asa result of research dissemination, along with the development of laws, policies, and guidelines, health care providers change their practice and treatment behaviors. These changes may be voluntary or regulated, but they are based on the knowledge accumulated through research conducted by NIEHSfunded investigators and others.

\section{Business and industry pathway}

This part of the logic model describes the inputs, activities, outputs, and outcomes directly associated with business and industry. It includes research and development activities leading to new commercial products and drugs, as well as the operational and infrastructure changes that industry makes in response to environmental and health hazards.

\section{Inputs}

Theinputs describethemajor relevant research areas of business and industry that may benefit from NIEHS-funded research, through product development or the use of results to adjust their operations. Industries included are a) health care and pharmaceutical companies, b) environmental science companies that prevent or reduce pollution and other environmental hazards, and c) regulated industries that may produce waste or byproducts that are pollutants, or d) other environmental hazards.

\section{Activities}

The activities in this submodel include the cooperative research conducted by business and industry with research partners; the development of health and environmental products and services such as drugs, medical devices, and monitors; and the use of research results by business and industry. Cooperative research with universities may contribute to investigator career development (in the grantee institution pathway). 
Outputs

Intellectual property developed by industry is protected by patents. As the result of research and the development of intellectual property, business and industry develop commercial products related to environmental health. These include drugs and medical products to address health issues, and sales of environmental controls and services.

\section{Outcomes}

The business and industry outcomes in the model includethefollowing:

. Short term: commercial products and drugs. The new commercial products developed by business and industry are then sold in the marketplace. Sales represent a short-term outcome becausethey reflect the amount of influence on health and the environment, as well as measuring benefit to the economy.

. Short term: awareness of environmental health impacts and proposed regulations. Business and industries that are subject to environmental regulations or that produce byproducts that are potential health hazards become aware of the accumulation of research results indicating their potential involvement in environmental health hazards. Outcomes related to this awareness are preregulatory and may include voluntary actions undertaken by companies to avoid legal action or community censure. Although voluntary actions by industry have been found to be limited in reducing emissions compared with mandatory approaches $^{15}$, we include them in the model as potential short-term pathway to change, given the political and administrative constraints to fashioning regulations.

- Intermediate: change in operations to reduce environmental hazards. Specific regulations and sometimes awareness of the environmental impacts of their products and actions encourage businesses and industries to reduce the hazards caused by their operations. These are intermediate outcomes because they are most often in response to laws, standards, and regulations.

. Long term: reduced environmental emissions. As in the government pathway, changes in regulatory standards should improve the natural environment. As the primary polluters or the manufacturers of consumer products that release pollutants, business and industry are the main actors in reducing emissions. There are many potential measuresfor long-term outcomes, including air pollutant emissions, hazardous waste land dispos- al, chemical discharges into water bodies, and releases of toxics to all media.

\section{Community pathway}

This pathway describes the inputs, activities, outputs, and outcomes associated with the community, the general public, that is influenced by or associated with NIEHS extramural funding. The community is also in itself a driver of environmental health impacts in that community activities apart from environmental health research can be a strong influence on broader public policies or research agendas, and promote actions by governmental agencies and business and industry. However, the goal of this model is to show possible mechanisms by which research can influence outcomes, rather than to depict a comprehensive view of how such outcomes may occur.

Inputs

The inputs describe the staff, financial, and organizational resources of the community and the public partners of NIEHS. In addition to individuals making up the general public, the community includes nongovernmental agencies addressing environmental health or environmental justice, community hospitals and clinics providing health care to the public, and schools.

\section{Activities}

Activities in this pathway are undertaken by the community and public as a result of NIEH S-funded research. The activities include participating in and/or facilitating community-based participatory research; outreach and education such as health fairs, information sessions, and educational forums; and training on environmental hazards to community members or groups such as first responders, teachers, industrial workers, and children/families.

\section{Outputs}

Community outreach including the wide dissemination of environmental health information to the general public, as well as development of public-private partnerships and community technology centers for the advancement of environmental health awareness, is themain output of this pathway. 


\section{Outcomes}

The community outcomesin themodel include the following:

. Short term: public awareness. Public awareness is an immediate outcome influenced in part by dissemination of NIEHS-funded research through accessible media.

. Intermediate: change in knowledge and attitudes. Asa result of awareness raised by NIEHSfunded research, the public's knowledge and attitudes about the environment, environmental justice, and environmental health issues may be positively influenced.

. Long term: public behavior changeand advocacy. Behavior change occurs as a result of changes in knowledge and attitudes about environmental health issues. It includes increased worker protection from environmental hazards; decreased use of toxics and hazardous materials at home, work, and school; decreased consumption of food and water with significant pollutant concentrations; decreased exposure to air pollutants; increased use of public transportation, car pools, and bicycles; and increased access to and awareness of relevant health care. It can also influence business and industry to change practices in response to consumer demand for less toxic and hazardous products.

\section{Ultimateoutcomes and contextual conditions}

The connection of research to the ultimate outcomes of improved human health involves multiple steps and actors. Typically, these outcomes would appear 10-50 years after the initial research, as new clinical practices, laws and regulations, and public behavioral changes are implemented and have an effect. The ultimate outcomes are related to the intermediate outcomes of all institutional pathways and fall into two categories: improved human health and well-being and benefit to theeconomy. Examples of ultimate outcomes related to improvement of human health include decreases in disease and injuries associated with exposures to adverse environmental health agents. Those associated with benefit to the economy include decreases in health care use, increases in worker productivity, and decreases in worker and school absenteeism due to symptoms and diseases associated with exposures to adverseenvironmental health agents. Less tangible are increases in value of natural resource goods, services, amenities, and intrinsic value from improved environment.

\section{Discussion}

The value of the logic model lies in its utility in developing pathways by which to link NIEHS funded research to ultimate outcomes. In addition, metrics associated with each component document the contribution. To illustrate the potential application of themodel, we present two brief examples for discussion. These examples demonstratea simplified approach of how to trace "forward" the influence that research may have on outcomes, even when that influence may be indirect, diffuse, or delayed. This approach does not attempt to identify all of the possible contributing factors to the noted impact.

Knowledge of the human health effects of ambient airborne pollutants has increased over the last several decades, from an initial focus on ozone and pulmonary diseases such as asthma, to a growing scientific understanding of the effects of fine airborne particulate matter (PM) on cardiovascular disease (e.g., Dockery ${ }^{16}$; D onaldson et al. ${ }^{17}$; Popeet al. ${ }^{18}$ ). For example, NIEHS-funded re searchers at Johns Hopkins University published results of mortality from fine PM in major U.S. cities ${ }^{19}$ and on hospital admissions related to fine $P M^{20}$. Subsequently, research results from these studies and others were disseminated by NIEHS and the institutions themselves through press releases (e.g., Johns H opkins University ${ }^{21}$; NIEH S ${ }^{22}$ ).

During the last decade, the U.S. EPA shifted its monitoring network to measure finer PM , specifically, PM with diameter less than $2.5 \mu \mathrm{m}$ (PM 2.5). The U.S. EPA revised its regulations to include an annual ambient standard for PM 2.5, conducting multiple stages of staff and public review of the new standard from the mid-1990s through 2006 (e.g., U.S. EPA ${ }^{23}$ ). NIEH S-funded research was cited in the regulatory docket (www.regulations.gov) of the later revisions as key evidence for the health effects of PM 2.5 (e.g., McConnell et al. ${ }^{24}$; Raizenne et al ${ }^{25}$; Schwartz et al. ${ }^{26}$ ). States are required to submit implementation plans to achieve compliance with thenew ambient standards; as part of these plans, state and local governments pass rules and regulations requiring industry and consumers to change their operations and reduce emissions. Reduced emissions required by thestate implementation plans will improve air quality to the new U.S. EPA standard by 2010.

In response to research documenting cardiovascular and other health effects, the U.S. EPA added fine PM to its air quality index reporting ${ }^{27}$ and specifically included cardiovascular effects in its public health messages ${ }^{28}$. Better knowledge of 
daily air pollution levels and the fact that thosewith heart disease are also at risk results in behavior modification by the public to reduce activity during pollution events ${ }^{29}$ and to advocate to re ducelocal emissions, thus resulting in reduced human exposure and mortality on high-pollutant days. Multiple studies (including some funded by NIEHS) over the last few decades contributed to and were cited by the EPA when setting and modifying the PM 2.5 standards.

As the influence is traced through the logic model, it becomes more diffuse and suffers from time discontinuities and lack of documentation. This exampleillustrates that, with a full evaluation and expert elicitation, it is possible to more specifically identify and semiquantify theimpact of NIEHS research, starting with this overview of potential influence. The case of lowered blood lead levels through phase-out of leaded gasoline and other lead-containing products demonstrates the influence of a pathway through the logic model related to the impact of government policy changes. The NIEHS has sponsored research on the health effects of lead for more than 20 years ${ }^{6}$. Be ginning in the 1970s, research funds from federal sources (vs. industry-sponsored studies) were allocated to the study of such health effects particularly in children [reviewed by Needleman ${ }^{30}$; N NEHS was a large supporter of these studies. Early studies showed that exposure to low levels of lead during early childhood can lead to delays in cognitive and behavioral development, such as lower IQ levels. Dissemination of these results was accomplished through early conferences and publications on lowlead toxicity; for example, an NIEHS-sponsored conference in 1974, the proceedings of which were published that same year in Environmental $\mathrm{H}$ ealth Perspectives. Information from studies like these added to the justification of the need to remove lead from gasoline starting in the 1970s. A criteria document, Air Quality Criteria for Lead ${ }^{31}$, assessed the scientific basis for regulation, and a standard of $1.5 \mathrm{ig} / \mathrm{m} 3$ (maximum quarterly calendar average) lead was set in $1978^{32}$. These air pollution regulations have removed significant amounts of lead from the environment ${ }^{33,34}$. Data from the second and third $\mathrm{N}$ ational $\mathrm{H}$ ealth and Nutrition Examination Studies show that between 1976 and 1980, there was an average drop in blood lead levels of $30 \%$, concurrent with a $50 \%$ reduction in use of leaded gasoline $e^{35}$. These trends have continued with an $86 \%$ drop in lead poisoning of children in theU nited States since the late 1970 s and other improve ments in health ${ }^{36,37}$. In this example, the NIEHS- funded research on blood lead levels supported ongoing regulations and contributed to the documentation of positive health effects.

The challenge of identifying a specific impact from a research program illustrated in these examples arises from how grant-funded research has an indirect benefit to and little substantial involvement by federal agencie ${ }^{38}$. Although fundamental research on both fine PM and blood lead levels contributed to awareness and monitoring of their relevant environmental health issue, the studies were not designed to set standards or to be used in policy decision making, except as an indirect contribution as aggregate knowledge. The $2004 \mathrm{Na}$ tional Research Council report on airborne PM identifies the synthesis of multipleresearch studies as a requirement for gauging research progress. Although independent research studies may beideal process for scientific discovery, structured logic models are needed to trace the diffuse yet important role of specific research programs.

\section{Conclusions}

The conceptual logic model for research metrics focuses on NIEHS-funded research programs to measure the contribution of environmental health research to improvements in human health, the environment, and the economy. The model is successfully illustrated here with two brief case examples: effects of PM and blood lead levels. In addition, this logic model approach has been applied to two full case studies- asthma and endocrine disruptors - as part of the larger study, the results of which are to be published separately. Furthermore, a database has been created that maps the logic model components and specific indicators to known published information, online databases, and document repositories that serve as sources of information for measuring outcomes for each logic model component. Although the main application of the logic model presented here was the environmental health research portfolio of NIEHS, its basic elements are applicable to other environmental or health research programs. The institutions that are part of the research processgovernment agencies, grantee institutions, business and industry, and community partnersare key players in nearly all environment and health programs. Despite the strengths of this approach, persistent challenges still remain. Theseincludethe lack of direct attribution of NIEH S-supported work to many of the outcome measures and the lack of robust electronic databases that can be easily 
searched to help establish theselinkages. M itigation of these problems will require a stronger effort to include better linkages to the primary literature/ grant support and organization of electronic information, particularly policy and/or health guidelines, in an easy format for indexing and searching. This can be achieved only by greater communication among all the stakeholders described in this logicmodel. Wehope that such dialogue will bestimulated by the present study. Finally, thislogic model narrows the focus to only one type of input- research-and its potential contribution to impacts.
Therefore, it does not attempt to demonstrate all of the many factors that may have contributed to a given impact. It is therefore important for the analyst using this model to not overstate the contribution of research to the impact versus other types of competing influences. The logic model has been developed to apply to diverseprograms within NIE$\mathrm{HS}$ and will beused as an ongoing program analysis tool. An area of further research is to apply the model to environment and health research programs at other government agencies, universities and research institutions, and private industry.

\section{Acknowledments}

WeacknowledgeA Powersfor her extensivework at the beginning of this project. Wegratefully acknowledge the assistance of $\mathrm{T}$ Bernichon, M Sill, $\mathrm{K}$ Versendaal, and M Wooton, all of Battelle. 
1. National Institute of Environmental $\mathrm{H}$ ealth Sciences. $\mathrm{N}$ ew Frontiers in Environmental $\mathrm{H}$ ealth Sciences and H uman Health. NIEHS 2006-2011 Strategic Plan. 2006. [accessed $1 \mathrm{M}$ arch 2007]. Available from: http://www.niehs.nih.gov/external/plan2006/Strategic Plan2006final.pdf

2. Office of $M$ anagement and Budget. Program Assessment Rating Tool Guidance No. 2006-02. $10 \mathrm{M}$ arch 2006. [accessed 12 December 2007]. Available from: http://www.whitehouse.gov/omb/part/2006_ part guidance.pdf

3. Cozzens $\mathrm{S}$. The knowledge pool: measurement challenges in evaluating fundamental research programs. Eval Program Plann 1997; 1:77-89.

4. Van Houten B, Phelps J, Barnes M, Suk W. Evaluating scientific impact. Environ Health Perspect 2000; 108: A392-A393.

5. Centers for Disease Control and Prevention. Introduction to Program Evaluation for Public H ealth Programs: A Self- Study Guide. Atlanta, GA: U.S. Centers for Disease Control and Prevention; 2005.

6. Department of Health and Human Services. HHS helps in efforts to eliminate childhood lead poisoning. U.S. Department of Health and Human Services. 2002 [accessed 4 April 2007]. Available from: http://www. hhs.gov/news/press/2002pres/lead.html

7. Chen H. Practical Program Evaluation: Assessing and Improving Planning, Implementation, and Effectiveness. Thousand Oaks, CA: Sage Publications; 2005.

8. M CLaughlin J, Jordan B. Logic models: a tool for telling your program's performance story. Eval Program Plann 1999; 22:65-72.

9. National Research Council. Research Priorities for Airborne Particulate Matter. IV: Continuing Research Progress. Committee on Research Priorities for Airborne Particulate M atter, Board on Environmental Studies and Toxicology, Division on Earth and Life Studies, National Research Council of the National Academies. Washington, D.C.: National Academies Press;2004.

10. Powers A, Rose S, Bernichon T, Engel-Cox J, Sill M, Versendaal K. Literature Review on Research Impact Assessment M ethods and Concepts. Work Assignment No. 1, Program Assessments and Evaluations for NIEHS. Contract H HSP23320045006XI, Task Order H HSP 233000015T. Arlington, VA: Battelle; 2006.

11. Buxton M, Hanney S. How can payback from health services research be assessed? J Health Serv Res Policy 1996; 1:35-43.

12. Hanney SR, Gonzalez-Block MA, Buxton MJ, Kogan $M$. The utilisation of health research in policy-making: concepts, examples and methods of assessment. Health Res Policy Syst 2003; 1:2.

13. Bozeman B. Public value mapping of science outcomes: theory and method. In: Bozeman B, Sarewitz D, Feinson S, Foladori G, Gaughan M, Gopta A, editors. Knowledge Flows and Knowledge Collectives: Understanding the Role of Science and Technology Policies in Development. Vol. 2. Washington, D.C.: Center for Science Policy and Outcomes; 2003. p. 3-48.
14. Rubenstein AH, Geisler E. The use of indicators and measures of the $R \& D$ process in evaluating science and technology programmes. In: Roessner JD, editor. Government Innovation Policy Design, Implementation, Evaluation. New York: St. M artins Press; 1988. p. 185203.

15. Morgenstern RD, Pizer WA, editors. Reality Check: The Nature and Performance of Voluntary Environmental Programs in the United States, Europe, and Japan. Washington, D.C.: RFF Press; 2007.

16. Dockery D. Epidemiologic evidence of cardiovascular effects of particulate air pollution. Environ $\mathrm{H}$ ealth Perspect 2001; 109(Suppl):483-486.

17. Donaldson K, Stone V, Seaton A, MacNee W. Ambient particle inhalation and the cardiovascular system: potential mechanisms. Environ Health Perspect 2001; 109 (Suppl 4):523-527.

18. Pope CA III, Burnett R, Thurston G, Thun M, Calle E, Krewski D.et, Godleski JJ. Cardiovascular mortality and long-term exposure to particulate air pollution: epidemiological evidence of general pathophysiological pathways of disease. Circulation 2004; 109:71-77.

19. Samet J, Dominici F, Curriero F, Coursac I, Zeger S. Fine particulate air pollution and mortality in 20 U.S. cities, 1987-1994. N Engl J M ed 2000; 343:1742-1749.

20. Dominici F, Peng D, Bell M, Pham L, McDermott $A$, Zeger S, Samet JM. Fine particulate air pollution and hospital admissions for cardiovascular and respiratory diseases. JAM A 2006; 295:1127-1134.

21. Johns Hopkins University. Particulate Air Pollution $\mathrm{N}$ eeds to Be Controlled to Protect Public Health. [Press release]. 2000 [accessed $17 \mathrm{M}$ ay 2007]. Available from: http://www.jhsph.edu/publichealthnews/press_releases /PR_2000/air_pollution_cities.html

22. National Institute of Environmental $\mathrm{H}$ ealth Sciences. Elderly Have Higher Risk for Cardiovascular, Respiratory Disease from Fine Particle Pollution. PR 06- 063/ 8/06. 2006 [accessed $17 \mathrm{M}$ ay 2007]. Available from: http://www.niehs.nih.gov/oc/news/ particle. htm

23. U.S. Environmental Protection Agency. Air Quality Criteria for Particulate M atter. EPA 600/P-99/002aF-bF. Washington, D.C.: U.S. Environmental Protection Agency; 2004.

24. McConnell R, Berhane K, Gilliland F, London S, Vora H, Avol E, Gauderman WJ, Margolis HG, Lurmann F, Thomas DC, Peters JM. Air pollution and bronchitic symptoms in Southern California children with asthma. Environ Health Perspect 1999; 107:757-760.

25. Raizenne $M$, Neas $L$, Damokosh A, Dockery D, Spengler J, Koutrakis P, Ware JH, Speizer FE. Health effects of acid aerosols on North American children: pulmonary function. Environ Health Perspect 1996; 104:506514.

26. Schwartz J, Norris G, Larson T, Sheppard L, Claiborne C, Koenig J. Episodes of high coarse particle concentrations are not associated with increased mortality. Environ Health Perspect 1999; 107:339-342.

27. U.S. Environmental Protection Agency. Air quality index reporting. Final rule. Fed Reg 40 CFR Part 58:4253042549. Washington, D.C.: U.S. Environmental Protection Agency; 1999. 
28. U.S. Environmental Protection Agency. Air Quality Index: A Guide to Air Quality and Your Health. EPA454/K-03-002. Washington, D.C.: U.S. Environmental Protection Agency; 2003.

29. Bresnahan B, Dickie M, Gerking S. Averting behavior and urban air pollution. Land Econ 1997; 73:340-357.

30. Needleman HL. The removal of lead from gasoline: historical and personal reflections. Environ Res 2000; 84:20-35.

31. U.S. Environmental Protection Agency. Air Quality Criteria for Lead. EPA-600/8-77-017. Research Triangle Park, NC:H ealth Effects Research Laboratory, Criteria and Special Studies Office, U.S. Environmental Protection Agency. Washington, D.C.: U.S. Environmental Protection Agency; 1977.

32. U.S. Environmental Protection Agency. National primary and secondary ambient air quality standards for lead. Fed Reg 40 CFR Part 50:46246-46277. Washington, D.C.: U.S. Environmental Protection Agency; 1978.

33. U.S. Environmental Protection Agency. EPA Takes Final Step in Phaseout of Leaded Gasoline. Washington, DC:U.S. Environmental Protection Agency; 1996. [accessed $31 \mathrm{M}$ arch 2007]. Available from: http://www.epa. gov/history/topics/lead/02.htm

34. U.S. Environmental Protection Agency. Latest Findings on National Air Quality: 2001 Status and Trends. U.S. Environmental Protection Agency. 2002 [accessed 7 May 2007]. Available from: http://www.epa.gov/ air/airtrends/aqtrnd02/ 2002 airtrends final.pdf

35. Annest J, Pirkle J, Makuc D, N eese J, Bayse D, Kovar $M$. Chronological trend in blood lead levels between 1976 and 1980. N Engl J Med 1983; 308:1373-1377.

36. Meyer P, Pivetz T, Dignam T, Homa D, Schoonover J, Brody D. Surveillance for elevated blood lead levels among children--U nited States, 1997-2001. M M WR Surveill Summ 2003; 52:1-21.

37. National Institute of Environmental Health Sciences. Low Levels of Lead and IQ Deficits. 2003 [accessed 4 April 2007]. Available from: http://www.niehs.nih.gov/ dert/profiles/hilites/2003/lead-IQ. htm

38. Federal Grants and Cooperative Agreement Act of 1977. Public Law 95-224.

Received 26 September 2007

Accepted 11 February 2008 